\title{
The secretome of endothelial progenitor cells: a potential therapeutic strategy for ischemic stroke
}

\author{
https://doi.org/10.4103/1673-5374.303012 \\ Date of submission: May 26, 2020 \\ Date of decision: July 28, 2020
}

Date of acceptance: November 6, 2020

Date of web publication: January 5, 2021

\author{
Mansour Alwjwaj, Rais Reskiawan A. Kadir, Ulvi Bayraktutan*
}

\begin{abstract}
Ischemic stroke continues to be a leading cause of mortality and morbidity in the world. Despite recent advances in the field of stroke medicine, thrombolysis with recombinant tissue plasminogen activator remains as the only pharmacological therapy for stroke patients. However, due to short therapeutic window ( 4.5 hours of stroke onset) and increased risk of hemorrhage beyond this point, each year globally less than $1 \%$ of stroke patients receive this therapy which necessitate the discovery of safe and efficacious therapeutics that can be used beyond the acute phase of stroke. Accumulating evidence indicates that endothelial progenitor cells (EPCS), equipped with an inherent capacity to migrate, proliferate and differentiate, may be one such therapeutics. However, the limited availability of EPCs in peripheral blood and early senescence of few isolated cells in culture conditions adversely affect their application as effective therapeutics. Given that much of the EPC-mediated reparative effects on neurovasculature is realized by a wide range of biologically active substances released by these cells, it is possible that EPC-secretome may serve as an important therapeutic after an ischemic stroke. In light of this assumption, this review paper firstly discusses the main constituents of EPC-secretome that may exert the beneficial effects of EPCs on neurovasculature, and then reviews the currently scant literature that focuses on its therapeutic capacity.

Key Words: antioxidants; cell-based therapy; cell-free therapy; endothelial progenitor cells; inflammatory cytokines; regenerative medicine; secretome; stroke; vasodegeneration; vasorepair
\end{abstract}

\section{Introduction}

According to the World Health Organization, each year about 15 million people suffer a first stroke in the world. Sadly, while one-third of these patients die, another onethird live with long-term disabilities inflicted by this condition (Ma et al., 2015). Hence, stroke continues to be one of the major causes of mortality and morbidity worldwide (Hisham and Bayraktutan, 2013; Liao et al., 2017). Ischemic strokes, stemming from an interruption of blood flow to the brain, make up about $80-85 \%$ of all strokes. Despite being the main cause of human cerebral damage, systemic thrombolysis with recombinant tissue plasminogen activator or endovascular treatment remain the only therapeutic options for this disease (Allen and Bayraktutan, 2009; Reis et al., 2017). However, due to short therapeutic window and stringent eligibility criteria, each year less than $1 \%$ of stroke patients worldwide receive either therapy (Hacke et al., 2008; Bayraktutan, 2019). This necessitates the discovery of novel therapeutic agents that can be safely and effectively used beyond the acute (or hyperacute) phase of ischemic stroke. Although over the years many agents targeting various mechanisms associated with ischemic stroke, such as excitotoxicity or oxidative stress, have generated favorable results in experimental settings, subsequent clinical trials have failed to replicate these favorable outcomes. As depicted in Figure 1, complexity of human neurovascular unit (NVU), a dynamic structure formed by direct contact, signaling and interactions amongst microglia, astrocytes, neurons and endothelial cells, has been proposed to explain this apparent dichotomy (Serlin et al.,
2015). Blood-brain barrier (BBB) makes up a critical part of this unit and is composed of brain microvascular endothelial cells (BMECs), capillary basement membrane (BM), pericytes embedded in the $\mathrm{BM}$ and astrocyte end-feet enclosing the blood vessels (Ballabh et al., 2004; Zehendner et al., 2009). Although its structural and functional integrity are critical in maintaining cerebrovascular homeostasis, the BBB is also an important obstacle for the delivery of so-called efficacious therapeutics. The BMECs cover the entire luminal part of all brain capillaries and constitute the main cellular component of the BBB. They differ from the endothelial cells of other organs in that they are joined together with tight junction proteins, lack fenestrae, have low number of intracellular mitochondria and possess specific transport systems that actively carry the nutrients from blood to the brain (Petty and Lo, 2002; Weiss et al., 2009). Tight junctions limit passive molecular diffusion through the BBB by forcing molecular traffic away from paracellular routes to transcellular routes (Wolburg and Lippoldt, 2002; Nag, 2003; Abbott et al., 2006). The BM surrounds the BMECs, accommodates pericytes, makes connections with astrocyte end-feet and appears to play a role in tight junction formation (Carvey et al., 2009). The pericytes enclose the blood vessel wall, make direct contact with the BMECs, facilitate angiogenesis and play a role in preserving microvascular stability (Zhao et al., 2015). The astrocyte end-feet enclose the outer side of the blood vessels, help maintain the integrity and function of the BBB and block the differentiation of pericytes from resting to a contractile stage (Yao et al., 2014). 


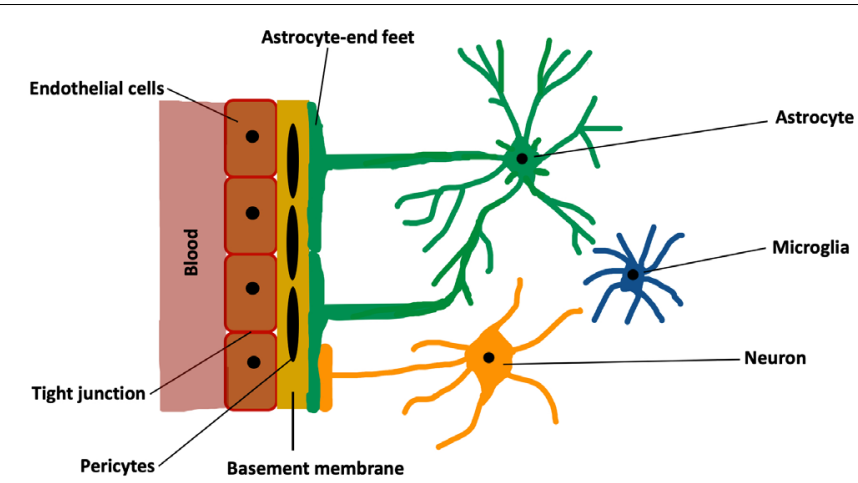

Figure 1 | Schematic representation of neurovascular unit.

Sudden decreases in cerebral blood flow during an ischemic stroke may perturb NVU structural integrity and impair overall cerebral function through involvement of a series of mechanisms including depleted generation of adenosine triphosphate, excitotoxicity, oxidative stress and inflammation (Lipton and Rosenberg, 1994; del Zoppo and Hallenbeck, 2000; Allan and Rothwell, 2001; Doyle et al., 2008; WilliamsKarnesky and Stenzel-Poore, 2009; Deb et al., 2010; Martin and Wang, 2010; Woodruff et al., 2011; Xing et al., 2012; Fann et al., 2013; Brennan-Minnella et al., 2015; Prakash and Carmichael, 2015). As illustrated in Figure 2, excitotoxicity harms NVU through increases in sodium and calcium influx triggered by accumulation of extracellular excitatory amino acids, glutamate and aspartate (Lipton and Rosenberg, 1994; Williams-Karnesky and Stenzel-Poore, 2009; Deb et al., 2010; Martin and Wang, 2010; Woodruff et al., 2011; Xing et al., 2012; Fann et al., 2013; Brennan-Minnella et al., 2015). Oxidative stress and post-ischemic inflammation, characterized by excessive availabilities of reactive oxygen species (ROS) and inflammatory cytokines such as interleukin (IL)-1 $\beta$, IL-18, IL-6 and tumor necrosis factor- $\alpha$ harm NVU by disrupting structural integrity of the tight junctions (del Zoppo and Hallenbeck, 2000; Allan and Rothwell, 2001; Doyle et al., 2008; Fann et al., 2013; Prakash and Carmichael, 2015).

\section{Search Strategy}

For the present review, we searched the literature using keywords such as endothelial progenitor cells, outgrowth endothelial cells, blood outgrowth endothelial cells, circulating endothelial colony forming cells, EPCs, OECs, secretome, growth factors, chemokines, cytokines, adhesion molecules, proteases, shed receptors, release, secrete, secretion, ischemia, infarction, vascular injury, endothelial injuries, reperfusion injury, stroke, cerebral damage, cerebrovascular disease, cerebral artery disease, and cerebrovascular accident on PubMed, Embase, Web of Sciences, Cochrane Central Library and Google Scholar. In addition, we also used modifications of the above main keywords to thoroughly search the literature. The major inclusion criteria preferred the literature comprising endothelial progenitor cells, secretome, ischemic stroke, and growth factors.

\section{Endothelial Progenitor Cells}

The inability to replicate favorable results obtained in translational studies has spurred stroke research community to explore new therapeutics that can simultaneously and effectively influence major mechanisms implicated in the pathogenesis of ischemic stroke (Deb et al., 2010). In this context, cell-based approaches, especially those with endothelial progenitor cells (EPCs) have attracted much of the attention (Condon et al., 2004; Di et al., 2009). EPCs are equipped with an inherent capacity to proliferate, migrate and differentiate into few other cells including mature endothelial cells. Considering that endothelial cells constitute

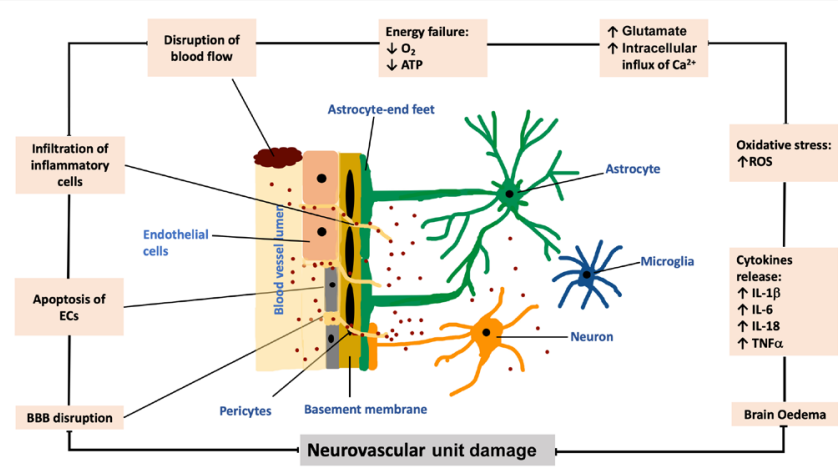

Figure 2 | Schematic representation of the effect of ischemic stroke on neurovascular unit.

A sudden disruption in cerebral blood flow and ensuing decreases in oxygen and energy supply triggers oxidative stress and compromises the integrities of tight junctions and blood-brain barrier (BBB). Overproduction of inflammatory cytokines and excitotoxicity further damage neuronal loss and BBB damage thereby leading to formation of cerebral edemas. ATP: Adenosine triphosphate; ECs: endothelial cells; IL: interleukin; ROS: reactive oxygen species; TNF $\alpha$ : tumor necrosis factor $\alpha$.

the main cellular component of the BBB and help maintain vascular homeostasis through regulation of vascular tone, coagulation and inflammation, replacement of dead or dying endothelial cells by EPCs is thought to be of considerable therapeutic value for patients with ischemic stroke. However, the sparsity of EPCs in circulation necessitates their isolation, characterization and expansion before re-administration as autologous or allogeneic therapeutics.

EPCs were first isolated as a subtype of peripheral blood mononuclear cells (Asahara et al., 1997) and later classified into two subtypes, early EPCs which appear after 3-5 days in culture, have spindle-shaped morphology and the late EPCs (also known as outgrowth endothelial cells (OECs)) which appear within 2-4 weeks after seeding and display cobblestone morphology (Hur et al., 2004; Bayraktutan, 2019). The OECs express angiogenic characteristics and are fully committed to the endothelial lineage (Medina et al., 2010). A recent study assessing the reparative impact of early EPCs and OECs on endothelial layer of a well-established in vitro model of human BBB, composed of endothelial cells, astrocytes and pericytes, has shown that only OECs can restore integrity and function of BBB by physical incorporation into the site of injury (Abdulkadir et al., 2020). In this regard, in vivo studies proving the safety and efficacy of autologous EPC transplantation also exist (Zhu et al., 2008). In addition to repairing damaged cerebral barrier, EPCs also contribute to neovascularization by modulating the content of their secretome and enhancing cell migration, proliferation and angiogenesis as a consequence (Kalka et al., 2000; Urbich et al., 2003, 2005a; Yamaguchi et al., 2003; Di et al., 2009; Gallina et al., 2015; Felice et al., 2018). As application of EPC-secretome may eliminate the risks associated with transplantation of live cells including emboli, infection and immune incompatibility, EPC-free approach may actually be a better therapeutic option. Table $\mathbf{1}$ summarizes the main benefits affiliated with treatments with EPCsecretome in that the possibility of an off-the-shelf application opens a new avenue in the field of regenerative medicine and deserves to be investigated as a potential therapeutic for ischemic stroke (Ballmoos et al., 2010; Seminatore et al., 2010; Lodi et al., 2011; Rosell et al., 2013; Vizoso et al., 2017).

\section{Analysis of Endothelial Progenitor Cell Secretome}

The term "secretome" is defined as a set of molecules, including of growth factors, chemokines, cytokines, free nucleic acids, lipids and extracellular vesicles, secreted or shed from living cells. The secretome may be stratified into 
Table 1 | Comparative impact of treatments with EPCs and EPC-secretome

EPCs therapy EPC-secretome therapy

\begin{tabular}{lll}
\hline Risk of infection & +++ & + \\
Risks of immune incompatibility & +++ & + \\
Emboli formation & ++ & + \\
$\begin{array}{l}\text { Need for toxic agents for } \\
\text { cryopreservation }\end{array}$ & ++ & + \\
Preparation time & ++ & + \\
Cost & ++ & + \\
\hline
\end{tabular}

EPCs: Endothelial progenitor cells.

microparticles, apoptotic bodies and exosomes (Tjalsma et al., 2000; Makridakis et al., 2010, 2013; Pavlou and Diamandis, 2010; Skalnikova et al., 2011; Beer et al., 2017). Of these, the exosomes are of particular interest due their ability to control intracellular communications by mediating the transfer of lipids, proteins or RNAs to the target cells. Exosomes are small vesicles that range between $40-150 \mathrm{~nm}$ in size (De Jong et al., 2014; Li et al., 2016). EPC-exosomes are surrounded by a bilayer of lipids and have a cup or biconcave morphology which protect them from enzymatic degradation and enable them to serve as transportation cargoes in the body (Yellon and Davidson et al., 2014; Vicencio et al., 2015; Kong et al., 2018). By increasing the expression of vascular endothelial growth factor (VEGF) and endothelial nitric oxide synthase, EPC-exosome appears to promote the survival, proliferation and tubulogenic activity of endothelial cells (Zhang et al., 2019) while inhibiting vascular leakage in lungs and kidneys (Zhou et al., 2018). Furthermore, EPC-exosome has been shown to inhibit neointima formation and enhance angiogenesis in both in vitro and in vivo settings like a rodent model of carotid artery injury (Sahoo et al., 2011; Kong et al., 2018). Recent evidence demonstrates that similar to EPCderived exosome, EPC-derived mitochondria also help protect NVU from ischemic damage by incorporating into endothelial cells and increasing intracellular adenosine triphosphate levels and tight junctional tightness (Hayakawa et al., 2018; Borlongan, 2019).

Like mature endothelial cells, EPCs are also able to secret a wide range of substances with different mechanism of action (Table $\mathbf{2}$ ). Shotgun proteomics and difference gel electrophoresis studies have identified 82 proteins in the conditioned media of human early EPCS (EPC-CM) which include various members of cathepsin family, proangiogenic substances like chemokine ligand 18, hemoglobin scavenger receptor CD163 and thymidine phosphorylase and few antioxidant enzymes such as mitochondrial superoxide dismutase and hemoxygenase-1 (Urbich et al., 2011). The 71 out of these 82 proteins in EPC-secretome appeared to be different from those of $\mathrm{CD} 14^{+}$monocytes and human umbilical veins endothelial cells (Urbich et al., 2011). By culturing cells in growth factor-free medium over a period of 72 hours, Rehman et al. (2003) have found that late EPCs release granulocyte colony-stimulating factor (G-CSF), VEGF, hepatocyte growth factor and granulocyte-macrophage colony-stimulating factor as angiogenic growth factors. Additional studies have shown that human EPC-CM also contains chemokines, thromboinflammatory mediators and adhesion molecules. Interestingly, while thrombo-inflammatory mediators such as tissue factors are secreted mainly by early EPCs, those regulate migration and infiltration of monocytes or macrophages, e.g., monocyte chemoattractant protein-1 are mainly released by late EPCs (Zhang et al., 2009). These add further weight to the previous studies indicating that early EPCs and OECs represent distinct EPC populations. Indeed, while cultured early EPCs express many genes linked to immunity and inflammation such as tolllike receptors, human leukocyte antigens and CD14 (Medina et al., 2010), OECs express the markers of senescence and produce greater levels of cytokines. Inflammatory elements such as IL-8, IL-6, IL-1 $\beta$ and IL- $1 \alpha$ have been identified as the major facilitators of OEC senescence (Medina et al., 2013). In light of the evidence, treatments with early EPC or OEC secretome should be conducted with care to avoid exacerbation of pre-existing inflammatory response in the ischemic microenvironment.

\section{Possible Mechanisms of Action of Endothelial Progenitor Cell Secretome in Ischemic Stroke} Anti-inflammatory activity

Inflammation, characterized by the exaggerated release of pro-inflammatory cytokines, e.g., IL-1 $\beta$, IL-6 and tumor necrosis factor- $\alpha$, represents one of the main mechanisms that develop following a cerebral ischemic injury. Stroke patients with localized (cerebral) or systemic inflammation exhibit clinically poorer outcome (Allan and Rothwell, 2001; Fann et al., 2013; Abdullah and Bayraktutan, 2016). Through concurrent regulation of various anti-inflammatory cytokines and inflammatory genes such as Brahma, IKB and Foxf1, EPCs attenuate the toxic and apoptotic tendencies of the inflammatory milieu. In support of this notion, co-culture of human EPCs with human endothelial cells has been shown to significantly block the elevations of aforementioned proinflammatory genes during experimental ischemic stroke. Likewise, intracerebral administration of late EPCs into animal model of ischemic stroke (after 4 hours) has also been shown to improve neurological recovery up to 30 days post celltherapy by significantly downregulating the gene expression of Brahma, IKB and Foxf1 in the cortex and striatum (Tajiri et al., 2012; dela Peña et al., 2015; Acosta et al., 2019). In accordance with these findings, administration of EPC-CM into a rat model of spinal cord injury has been found to induce functional recovery where attenuation of apoptosis, M1 macrophage activation and IL-6 release along with stimulation of angiogenesis appeared to aid functional recovery (Wang et al., 2018). Similar to these observations, intratracheal administration of EPC-exosome to a mice model of acute lung injury has also significantly reduced chemokine, cytokine and protein concentrations in the bronchoalveolar lavage fluid, further supporting the anti-inflammatory and tissue-protective effects of EPC-secretome (Zhou et al., 2019). In another study, reinfusion of a specific paracrine factor, namely thymosin B4 released by embryonic EPCs has diminished infarct size in pigs subjected to myocardial ischemia and enhanced posthypoxic cardiomyocyte survival by moderating post-ischemic inflammatory responses (Hinkel et al., 2008).

\section{Tissue repair and angiogenic regulation}

Discovery of an abundance of highly mitogenic cytokines, notably IL-8 and angiogenin in EPC-CM strongly implies that EPC-secretome can readily stimulate the chemotactic, proliferative and tubulogenic capacity of endothelial cells (He et al., 2005). Post-stroke administration of EPCsecretome rich in angiogenic factors may help facilitate vascular repair and suppress neointima formation by inducing proliferation of the resident endothelial cells at the site of vascular damage (Paneni et al., 2016). It is of note here that the process of angiogenesis, involving the activation and migration of endothelial cells, is also regulated by cytokines and chemokines (Gnecchi et al., 2008). Transplantation of OEC-secretome rich in cytokines and chemokines has been coupled to marked increases in the angiogenic capacity of brain BMECs in a mouse model of chronic cerebral hypoperfusion and in in vitro settings (Di Santo et al., 2014). Furthermore, greater availability of different growth factors such as VEGF and IGF-1 has also been implicated in increased angio-neurogenesis in the ischemic area of stroke rats treated with late EPCs (Urbich et al., 2005b; Moubarik et al., 2011; Schneller et al., 2019). 
Table 2 | Important paracrine factors of endothelial progenitor cell-secretome

\begin{tabular}{|c|c|c|}
\hline Factors & Function & References \\
\hline Angiogenin & Angiogenesis, migration, proliferation & Di Santo et al. (2009); Maki et al. (2018) \\
\hline Hepatocyte growth factor & Angiogenesis, motility, morphogenesis & Rehman et al. (2003); Di Santo et al. (2009) \\
\hline Interleukin-8 & Chemoattraction, proliferation, angiogenesis & Urbich et al. (2005); Di Santo et al. (2009); Pula et al. (2009) \\
\hline Platelet derived growth factor B & Angiogenesis, proliferation, recruitment & Di Santo et al. (2009) \\
\hline Stromal derived factor-1 & Angiogenesis, antipoptosis, migration & Di Santo et al. (2009); Paneni et al. (2016); Maki et al. (2018) \\
\hline Vascular endothelial growth factor & Migration, proliferation, angiogenesis & Rehman et al. (2003) \\
\hline Vascular endothelial growth factor A & Migration, mitogenesis, angiogenesis & Urbich et al. (2005); Di Santo et al. (2009); \\
\hline Pre-B cell-enhancing factor & Angiogenesis, antipoptosis & Pula et al. (2009) \\
\hline Matrix metalloproteinase- 9 & Angiogenesis, migration, proliferation & Rehman et al. (2003); Pula et al. (2009) \\
\hline Macrophage migration inhibitory factor & Angiogenesis, migration, recruitment & Pula et al. (2009) \\
\hline Cathepsins & Invasion, angiogenesis & Urbich et al. (2005); Pula et al. (2009); Urbich et al. (2011) \\
\hline Protease inhibitors & Angiogenesis, migration, invasion & Pula et al. (2009) \\
\hline S100 proteins & Angiogenesis, proliferation, invasion & Pula et al. (2009) \\
\hline Thymidine phosphorylase & Angiogenesis, antipoptosis, migration & Pula et al. (2009) \\
\hline 2-deoxy-D-ribose-1-phosphate & Migration, angiogenesis & Pula et al. (2009) \\
\hline Mitochondrial superoxide dismutase & Antioxidants, antipoptosis & Dernbach et al. (2004); Urbich et al. (2011) \\
\hline Homoxygenase-1 & Antioxidant, antipoptosis & Dernbach et al. (2004); Urbich et al. (2011) \\
\hline $\begin{array}{l}\text { Alternative macrophage markers } \mathrm{C}-\mathrm{C} \text { motif } \\
\text { chemokine } 18\end{array}$ & Healing, migration & Urbich et al. (2011) \\
\hline Haemoglobin scavenger receptor CD163 & Adhesion, anti-inflammation & Urbich et al. (2011) \\
\hline Cytokine-like 1 & Angiogenesis, migration & Schneller et al. (2019) \\
\hline Platelet-derived growth factor $\mathrm{AA} / \mathrm{AB} / \mathrm{BB}$ & Angiogenesis, proliferation, recruitment & Urbich et al. (2005); Maki et al. (2018) \\
\hline Vascular endothelial growth factor B & Angiogenesis, migration & Urbich et al. (2005); Maki et al. (2018) \\
\hline $\begin{array}{l}\text { Granulocyte-macrophage colony-stimulating } \\
\text { factor }\end{array}$ & Angiogenesis, proliferation, antipoptosis & Rehman et al. (2003) \\
\hline Granulocyte colony-stimulating factor & Proliferation, differentiation, angiogenesis & Rehman et al. (2003); De Jong et al. (2014) \\
\hline
\end{tabular}

\section{Antioxidant capacity}

Oxidative stress, emerging from an imbalance between pro- and anti-oxidants, is another major mechanism that can induce or worsen cerebrovascular damage following an ischemic cerebral injury (Allen and Bayraktutan, 2009). Compared to mature endothelial cells, EPCs possess significantly higher total antioxidant capacity. Indeed, greater expression of antioxidant enzyme glutathione peroxidase, $\mathrm{Mn}$ containing superoxide dismutase and catalase enables EPCs to tolerate a certain degree of oxidative stress (Dernbach et al., 2004) and potentiates their vasoreparative and angiogenic capacities in both ischemic and inflammatory settings. For instance, treatments with late EPC-secretome has been shown to mitigate the deleterious effects of oxidative stress on BBB during and after an ischemic stroke (Dernbach et al., 2004) and reduced the extent of oxidative injury in human umbilical veins endothelial cells by augmenting the expression of antioxidant enzymes, $\mathrm{Mn}$ - and CuZn-containing superoxide dismutase (Yang et al., 2011).

\section{Migration and tissue invasion}

EPCs also regulate cellular chemotaxis by modulating the release of prominent pro-angiogenic factors like VEGF, SDF1, IGF-1 and hepatocyte growth factor. Increases in VEGF and SDF-1 also facilitate adhesion and recruitment of EPCs to the site of ischemic and non-ischemic damage (Anderson et al., 2015). Similarly, EPC-secretome has been shown to increase mobilization, proliferation and migration of various progenitor and resident vascular cells like cardiac progenitor cells and endothelial cells, respectively. Increased migration of mature endothelial cells to the site of limb ischemia in rats treated with human EPC-CM corroborates this notion (Urbich et al., 2005a).

Apart from growth factors and cytokines, EPCs also synthesize and release many lysosomal peptidases including cathepsin $\mathrm{L}$, cathepsin $\mathrm{D}$, cathepsin $\mathrm{H}$ and cathepsin $\mathrm{O}$. Bearing in mind that inhibition of these enzymes, in particular that of cathepsin $L$, has abated the invasion, incorporation and function of EPCs in a model of hindlimb ischemia (Urbich et al., 2005b), specific targeting of these peptidases may prove to be instrumental in controlling the recruitment of EPCs to the site of injury. It is possible that EPC-secretome supplemented with cathepsin $L$ may substantially induce homing and incorporation of circulating EPCs to the site of ischemic cerebral injury. Figure 3 summarizes potential mechanism of action of EPC secretome on NVU during and after ischemic stroke.

\section{Key Mechanisms Associated with Modification of Endothelial Progenitor Cell Secretome}

Hypoxia is regarded as the main element that can enhance the migratory and angiogenic capacities of transplanted cells (Wei et al., 2012; Morancho et al., 2013). As exposure of EPCs to hypoxia promotes secretion of a series of growth factors, notably VEGF, VEGF-D, PDGF-BB, epidermal growth factor, basic fibroblast growth factor as well as angiogenin, leptin and thrombopoietin, it is likely that CM obtained from EPCs subjected to hypoxia can augment the regenerative potential of native and transplanted progenitor cells (Di Santo et al., 2014). Indeed, such treatment has recently been shown to induce mobilization of EPCs from bone marrow and led to increases in hindlimb blood flow and capillary density while inhibiting apoptosis of mature endothelial cells (Di Santo et al., 2009). Furthermore, application of hypoxic EPC$\mathrm{CM}$ entrapped in polymer-based nanoparticles, carriers for controlled release of EPC secretome, has also been shown to increase blood perfusion and capillary formation in ischemic limb model (Felice et al., 2018). EPCs grown under hypoxic conditions have been shown to secrete 647 proteins. Of these, 83 appear to be differentially regulated compared to the cells grown under normoxic conditions. While the expression of 17 of these 83 proteins, mostly angiogenic factors including protein S100 family, apolipoprotein E, protease inhibitors are upregulated by hypoxia, the expression of 12 proteins, notably dermcidin, trypsin-1, cystatin-C and calcium-binding protein 39 appear to be downregulated (Felice et al., 2018).

Inflammation or inflammatory reactions can also influence 


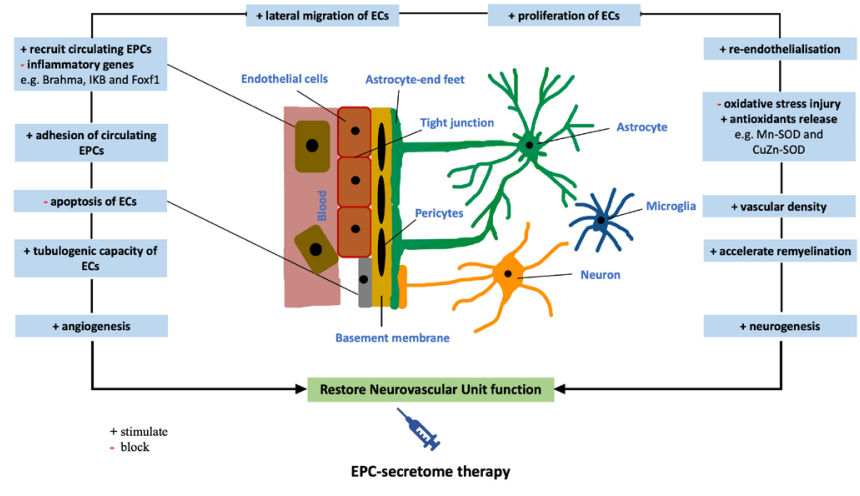

Figure 3 | Possible mechanism of action of EPC secretome on restoration of neurovascular unit during or after an ischemic stroke.

EPC-secretome containing many biologically active substances such as growth factors, cathepsins, cytokines and chemokines may evoke endogenous regeneration and neovascularization by activating resident endothelial cells, inhibiting oxidative stress and concomitantly inducing angiogenesis and neurogenesis. EC: Endothelial cell; EPC: endothelial progenitor cell.

the number and functionality of EPCs. Inflammatory factors such as GM-CSF and SDF-1 enhance mobilization of EPCs from bone marrow (Takahashi et al., 1999; Tousoulis et al., 2008). For example, the increases seen in number of functional late OECs mirrored increases in plasma levels of VEGF, SDF-1 and IL-8 in burned patients within the first 24 hours of hospital admission (Rignault-Clerc et al., 2013). Another study focusing on the mobilization of EPCs in two different groups of patients with acute vascular injury emerging from burns or coronary artery bypass grafting has also revealed substantial increases in circulatory EPC numbers and coupled these to significant increases in plasma VEGF and cytokine levels (Gill et al., 2001). These findings suggest that enrichment of EPC-secretome by exposure to inflammatory stimuli in in vitro settings may potentiate its therapeutic impact in in vivo settings through recruitment of resident EPCs from bone marrow to the site of ischemic injury.

As indicated above, oxidative stress radically contributes to the pathogenesis and progression of ischemic stroke. Genetic manipulation of factors associated with the release or neutralization of ROS is therefore likely to influence the content of EPC-secretome and its therapeutic efficacy. Mammalian adaptor p66Shc and JunD, a member of the activated protein-1 family of transcription factors which modulate mitochondrial ROS production and vascular cell senescence have attracted some attention in this context. Indeed, compared to OECs obtained from young donors, OECs of old subjects express significantly higher levels of p66Shc (pro-oxidant) and the lower level of the activated protein-1. However, genetic manipulation of OECs isolated from elderly donors through silencing of p66Shc or overexpression of JunD has been shown to attenuate age-driven ROS generation by reinstating a balance between pro-oxidant and anti-oxidant enzymes and enhance SDF-1 expression in conditioned media (Paneni et al., 2016).

\section{Therapeutic Potential of Endothelial Progenitor Cell Secretome}

Considering that proteins secreted into conditioned media in in vitro conditions mimicking an ischemic injury are likely to be representative of those found in circulation following a cerebral ischemic episode, their analysis and accurate identification are of profound diagnostic, prognostic and therapeutic importance (Stastna and Van Eyk, 2012). In light of the reports illustrating post-ischemic increases in circulating numbers of EPCs, it is safe to propose that similar increases in the synthesis and release of constituents that make up EPC-secretome may also go up which in turn substantiate their diagnostic value (Sobrino et al., 2007). While regenerative potential of EPC-secretome is somewhat well-documented in experimental settings, to our knowledge there is currently no clinical study that has assessed the putative therapeutic role of EPC-secretome after an ischemic stroke. In fact, phase I and phase II clinical trials of intravenous transplantation of allogenic mesenchymal stem cells for patients with chronic ischemic stroke (> 6 months of onset) have been shown to be safe and associated with significant behavioral gain over a 12-month follow up (Levy et al., 2019). As the microenvironment affecting the NVU after an ischemic stroke is under persistent change (Liao et al., 2017), while designing prospective clinical trials, the timing of treatments with EPC-secretome is an important factor to take into consideration. Transplantation of EPCs or EPCsecretome rich in VEGF, PDGF-BB and fibroblast growth factor into a mouse model of ischemic stroke, within 30-32 hours of ischemic stroke, has been shown to enhance capillary density in the peri-infarct areas and improved functional strength of forelimbs. The improvements in functional aspects remained noticeable at 2 weeks following ischemic injury and were largely attributed to the appearance of additional blood vessels in the peri-infarct areas (Rosell et al., 2013). Intravenous injection of EPCs into a rodent model of transient ischemic stroke 24 hours after the occlusion of middle cerebral artery also led to a significant functional recovery within two weeks. Given that the direct incorporation of EPCs into rat neovasculature could not be visualized in this study, functional improvements observed might actually be due to the paracrine effects of EPC-secretome (Moubarik et al., 2011). A relevant study testing the angiogenic capacity of early (within 1 hour of stroke) and late (48 hours after stroke) administration of VEGF, a key component of EPC-secretome, to a rodent model of ischemic stroke has generated some interesting findings in that while the former approach compromised the integrity of the $\mathrm{BBB}$ and promoted hemorrhagic transformation in the focal ischemic lesions, the latter approach enhanced angiogenesis in the ischemic penumbra and significantly improved neurological recovery. Taken together these findings imply that future therapeutic strategies considering exogenous administration of EPC-secretome should pay a very close attention to the treatment start time and adjust the concentration of EPCsecretome according to the phase of ischemic stroke; hyperacute, acute, subacute versus chronic (Zhang et al., 2000).

Similar to the beneficial effects observed after ischemic stroke, EPC-derived factors have been shown to protect cultured cortical neuronal progenitor cells from a metabolic injury induced by glucose and serum deprivation (Santo et al., 2020). Again, transplantation of EPCs to a mice model of traumatic brain injury led to elevations in neovasculogenesis and neurological recovery. Here, stimulation of axonal outgrowth of neurons along with increased proliferation, survival and recruitment of resident EPCs to the site of ischemic brain injury by key constituents of EPC secretome, namely VEGF, SDF1 and proangiogenic cytokines, was thought to play a critical role (Zhang et al., 2013). EPC secretome-mediated suppression of inflammation alongside the regulation of angiogenesis, functional recovery and axonal regeneration has also been implicated in neuroprotection in a rat model of spinal cord injury (Wang et al., 2018). Furthermore, intravenous administration of EPC-secretome to mice at 24 hours and 7 days of permanent bilateral occlusion of carotid arteries has also been associated with promotion of vascular density and protection of cognitive function in a mouse model of white matter injury following prolonged cerebral hypoperfusion (Maki et al., 2018). In light of these studies, it is reasonable to suggest that administration of EPC-secretome to patients with ischemic stroke beyond the hyperacute phase of the disease may be beneficial. Table 3 summarizes the major benefits of EPC-secretome in pre-clinical settings. 


\section{Review}

Table 3 | Therapeutic effects of EPC-secretome on various conditions

\begin{tabular}{|c|c|c|c|}
\hline Study & Study design & Route of administration & Major effects \\
\hline $\begin{array}{l}\text { Rosell et al. } \\
(2013)\end{array}$ & $\begin{array}{l}\text { EPC-CM injected to a mouse model of ischemic } \\
\text { stroke }\end{array}$ & $200 \mu \mathrm{L}$ intravenous & $\begin{array}{l}\text { Enhanced neurobehavioral outcomes, capillary density of peri- } \\
\text { infarct areas, and improved functional strengths of forelimbs. }\end{array}$ \\
\hline $\begin{array}{l}\text { Kong et al. } \\
(2018)\end{array}$ & $\begin{array}{l}\text { EPC-exosome injected to a rat model of carotid } \\
\text { artery injury. }\end{array}$ & $30 \mu g$ intravenous & Prevented neointima formation. \\
\hline $\begin{array}{l}\text { Wang et al. } \\
\text { (2018) }\end{array}$ & $\begin{array}{l}\text { EPC-CM injected to a rat model of spinal cord } \\
\text { injury. }\end{array}$ & $1 \mathrm{~mL}$ intraperitoneal & Induced recovery of motor function of bilateral hind limb. \\
\hline Li et al. (2016) & $\begin{array}{l}\text { EPC-exosome injected to a rat model of } \\
\text { balloon-induced carotid injury. }\end{array}$ & $30 \mu \mathrm{g}$ intravenous & Accelerated early re-endothelialization. \\
\hline $\begin{array}{l}\text { Maki et al. } \\
\text { (2018) }\end{array}$ & $\begin{array}{l}\text { EPC-secretome given to mice subjected to } \\
\text { permanent bilateral carotid artery stenosis. }\end{array}$ & $160 \mu \mathrm{L}$ intravenous & $\begin{array}{l}\text { Enhanced vascular density, myelin, and mature oligodendrocytes in } \\
\text { white matter and rescued cognitive function. }\end{array}$ \\
\hline
\end{tabular}

CM: Culture medium; EPC: endothelial progenitor cell.

\section{Conclusion}

It is evident that EPCs secrete a vast range of substances with differing function. Evidence gathered from an increasing number of in vitro and in vivo studies suggest that these factors may help repair the damaged neurovasculature after an ischemic stroke by inducing mobilization, proliferation, migration and homing of resident or circulatory progenitor cells to the damaged vasculature. Available evidence also indicates that timing of post-stroke administration of EPCsecretome is of crucial importance to improve neurological outcome and to prevent hemorrhagic transformation. However, well-thought future studies scrutinizing the therapeutic potential and efficacy of EPC-secretome in laboratory, translational and clinical settings are required before a cell-free treatment regimen can become a therapeutic possibility for patients with ischemic stroke.

Author contributions: Literature retrieval and manuscript preparation: $M A$; manuscript review and review guiding: RRA; review conception and manuscript editing: UB. All authors approved the final version of this manuscript.

Conflicts of interest: The authors declare that they have no conflicts of interest.

Financial support: None.

Copyright license agreement: The Copyright License Agreement has been signed by all authors before publication.

Plagiarism check: Checked twice by iThenticate.

Peer review: Externally peer reviewed.

Open access statement: This is an open access journal, and articles are distributed under the terms of the Creative Commons AttributionNonCommercial-ShareAlike 4.0 License, which allows others to remix, tweak, and build upon the work non-commercially, as long as appropriate credit is given and the new creations are licensed under the identical terms.

\section{References}

Abbott NJ, Ronnback L, Hansson E (2006) Astrocyte-endothelial interactions at the bloodbrain barrier. Nat Rev Neurosci 7:41-53.

Abdulkadir RR, Alwjwaj M, Othman OA, Rakkar K, Bayraktutan U (2020) Outgrowth endothelial cells form a functional cerebral barrier and restore its integrity after damage. Neural Regen Res 15:1071-1078.

Abdullah Z, Bayraktutan U (2016) Suppression of PKC- $\alpha$ attenuates TNF- $\alpha$-evoked cerebral barrier breakdown via regulations of MMP-2 and plasminogen-plasmin system. Biochim Biophys Acta 1862:1354-1366

Acosta SA, Lee JY, Nguyen H, Kaneko Y, Borlongan CV (2019) Endothelial progenitor cells modulate inflammation-associated stroke vasculome. Stem Cell Rev Rep 15:256-275. Allan SM, Rothwell NJ (2001) Cytokines and acute neurodegeneration. Nat Rev Neurosci 2:734-744

Allen CL, Bayraktutan U (2009) Oxidative stress and its role in the pathogenesis of ischaemic stroke. Int J Stroke 4:461-470

Anderson EM, Kwee BJ, Lewin SA, Raimondo T, Mehta M, Mooney DJ (2015) Local delivery of VEGF and SDF enhances endothelial progenitor cell recruitment and resultant recovery from ischemia. Tissue Eng Part A 21:1217-1227.

Asahara T, Murohara T, Sullivan A, Silver M, van der Zee R, Li T, Witzenbichler B, Schatteman G, Isner JM (1997) Isolation of putative progenitor endothelial cells for angiogenesis. Science 275:964-967.

Ballabh P, Braun A, Nedergaard M (2004) The blood-brain barrier: an overview: structure, regulation, and clinical implications. Neurobiol Dis 16:1-13.

Ballmoos MWV, Yang Z, Jan Völzmann, Baumgartner I, Kalka C, Santo SD (2010) Endothelial progenitor cells induce a phenotype shift in differentiated endothelial cells towards pdgf/pdgfr $\beta$ axis-mediated angiogenesis. PLoS One 5:e14107.

Bayraktutan U (2019) Endothelial progenitor cells: potential novel therapeutics for ischaemic stroke. Pharmacol Res 144:181-191.
Beer L, Mildner M, Ankersmit HJ (2017) Cell secretome based drug substances in regenerative medicine: when regulatory affairs meet basic science. Ann Transl Med 5:170.

Borlongan CV (2019) Concise review: stem cell therapy for stroke patients: are we there yet? Stem Cells Transl Med 8:983-988.

Brennan-Minnella AM, Won SJ, Swanson RA (2015) NADPH oxidase-2: linking glucose, acidosis, and excitotoxicity in stroke. Antioxid Redox Signal 22:161-174.

Carvey PM, Hendey B, Monahan AJ (2009) The blood-brain barrier in neurodegenerative disease: a rhetorical perspective. J Neurochem 111:291-314.

Condon ET, Wang JH, Redmond HP (2004) Surgical injury induces the mobilization of endothelial progenitor cells. Surgery 135:657-661.

De Jong OG, Van Balkom BW, Schiffelers RM, Bouten CV, Verhaar MC (2014) Extracellular vesicles: potential roles in regenerative medicine. Front Immunol 5:608.

Deb P, Sharma S, Hassan KM (2010) Pathophysiologic mechanisms of acute ischemic stroke: An overview with emphasis on therapeutic significance beyond thrombolysis. Pathophysiology 17:197-218

del Zoppo GJ, Hallenbeck JM (2000) Advances in the vascular pathophysiology of ischemic stroke. Thromb Res 98:73-81.

dela Peña IC, Yoo A, Tajiri N, Acosta SA, Ji X, Kaneko Y, Borlongan CV (2015) Granulocyte colony-stimulating factor attenuates delayed tPA-induced hemorrhagic transformation in ischemic stroke rats by enhancing angiogenesis and vasculogenesis. J Cereb Blood Flow Metab 35:338-346.

Dernbach E, Urbich C, Brandes RP, Hofmann WK, Zeiher AM, Dimmeler S (2004) Antioxidative stress-associated genes in circulating progenitor cells: evidence for enhanced resistance against oxidative stress. Blood 104:3591-3597.

Di Santo S, Seiler S, Fuchs AL, Staudigl J, Widmer HR (2014) The secretome of endothelial progenitor cells promotes brain endothelial cell activity through PI3-kinase and MAPkinase. PLoS One 9:e95731.

Di Santo S, Yang Z, Wyler von Ballmoos M, Voelzmann J, Diehm N, Baumgartner I, Kalka C (2009) Novel cell-free strategy for therapeutic angiogenesis: in vitro generated conditioned medium can replace progenitor cell transplantation. PLoS One 4:e5643.

Doyle KP, Simon RP, Stenzel-Poore MP (2008) Mechanisms of ischemic brain damage. Neuropharmacology 55:310-318.

Fann DY, Lee SY, Manzanero S, Chunduri P, Sobey CG, Arumugam TV (2013) Pathogenesis of acute stroke and the role of inflammasomes. Ageing Res Rev 12:941-966.

Felice F, Piras AM, Rocchiccioli S, Barsotti MC, Santoni T, Pucci A, Burchielli S, Chiellini F, Ucciferri N, Solaro R, Altomare A, Cecchettini A, Di Stefano R (2018) Endothelia progenitor cell secretome delivered by novel polymeric nanoparticles in ischemic hindlimb. Int J Pharm 542:82-89.

Gallina C, Turinetto V, Giachino C (2015) A new paradigm in cardiac regeneration: the mesenchymal stem cell secretome. Stem Cells Int 2015:765846.

Gill M, Dias S, Hattori K, Rivera ML, Hicklin D, Witte L, Girardi L, Yurt R, Himel H, Rafil $S$ (2001) Vascular trauma induces rapid but transient mobilization of VEGFR2(+) AC133(+) endothelial precursor cells. Circ Res 88:167-174

Gnecchi M, Zhang Z, Ni A, Dzau VJ (2008) Paracrine mechanisms in adult stem cell signaling and therapy. Circ Res 103:1204-1219.

Hacke W, Kaste M, Bluhmki E, Brozman M, Dávalos A, Guidetti D, Larrue V, Lees KR, Medeghri Z, Machnig T, Schneider D, von Kummer R, Wahlgren N, Toni D; ECASS Investigators (2008) Thrombolysis with alteplase 3 to 4.5 hours after acute ischemic stroke. N Engl J Med 359:1317-1329.

Hayakawa K, Chan SJ, Mandeville ET, Park JH, Bruzzese M, Montaner J, Arai K, Rosell A Lo EH (2018) Protective effects of endothelial progenitor cell-derived extracellular mitochondria in brain endothelium. Stem Cells 36:1404-1410

He T, Peterson TE, Katusic ZS (2005) Paracrine mitogenic effect of human endothelial progenitor cells: role of interleukin-8. Am J Physiol Heart Circ Physiol 289:H968-972.

Hinkel R, El-Aouni C, Olson T, Horstkotte J, Mayer S, Müller S, Willhauck M, Spitzweg C, Gildehaus FJ, Münzing W, Hannappel E, Bock-Marquette I, DiMaio JM, Hatzopoulos AK, Boekstegers P, Kupatt C (2008) Thymosin beta4 is an essential paracrine factor of embryonic endothelial progenitor cell-mediated cardioprotection. Circulation 117:2232-2240

Hisham NF, Bayraktutan U (2013) Epidemiology, pathophysiology, and treatment of hypertension in ischaemic stroke patients. J Stroke Cerebrovasc Dis 22:e4-14

Hur J, Yoon CH, Kim HS, Choi JH, Kang HJ, Hwang KK, Oh BH, Lee MM, Park YB (2004) Characterization of two types of endothelial progenitor cells and their different contributions to neovasculogenesis. Arterioscler Thromb Vasc Biol 24:288-293.

Kalka C, Masuda H, Takahashi T, Kalka-Moll WM, Silver M, Kearney M, Li T, Isner JM, Asahara T (2000) Transplantation of ex vivo expanded endothelial progenitor cells for therapeutic neovascularization. Proc Natl Acad Sci U S A 97:3422-3427.

Kong J, Wang F, Zhang J, Cui Y, Pan L, Zhang W, Wen J, Liu P (2018) Exosomes of endothelial progenitor cells inhibit neointima formation after carotid artery injury. J Surg Res 232:398-407.

Levy ML, Crawford JR, Dib N, Verkh L, Tankovich N, Cramer SC (2019) Phase I/II study of safety and preliminary efficacy of intravenous allogeneic mesenchymal stem cells in chronic stroke. Stroke 50:2835-2841. 
Li X, Chen C, Wei L, Li Q, Niu X, Xu Y, Wang Y, Zhao J (2016) Exosomes derived from endothelial progenitor cells attenuate vascular repair and accelerate reendothelialization by enhancing endothelial function. Cytotherapy 18:253-262.

Liao S, Luo C, Cao B, Hu H, Wang S, Yue H, Chen L, Zhou Z (2017) Endothelial progenito cells for ischemic stroke: update on basic research and application. Stem Cells Int 2017:2193432.

Lipton SA, Rosenberg PA (1994) Excitatory amino acids as a final common pathway for neurologic disorders. N Engl J Med 330:613-622.

Lodi D, lannitti T, Palmieri B. Stem cells in clinical practice: applications and warnings (2011) J Exp Clin Cancer Res 30:9.

Ma F, Morancho A, Montaner J, Rosell A (2015) Endothelial progenitor cells and revascularization following stroke. Brain Res 1623:150-159.

Maki T, Morancho A, Martinez-San Segundo P, Hayakawa K, Takase H, Liang AC, Gabriel Salazar M, Medina-Gutiérrez E, Washida K, Montaner J, Lok J, Lo EH, Arai K, Rosell A (2018) Endothelial progenitor cell secretome and oligovascular repair in a mouse model of prolonged cerebral hypoperfusion. Stroke 49:1003-1010.

Makridakis M, Roubelakis MG, Vlahou A (2013) Stem cells: insights into the secretome. Biochim Biophys Acta 1834:2380-2384

Makridakis M, Vlahou A (2010) Secretome proteomics for discovery of cancer biomarkers. J Proteomics 73:2291-2305.

Martin HG, Wang YT (2010) Blocking the deadly effects of the NMDA receptor in stroke. Cell 140:174-176.

Medina RJ, O'Neill CL, O'Doherty TM, Chambers SE, Guduric-Fuchs J, Neisen J, Waugh DJ, Simpson DA, Stitt AW (2013) Ex vivo expansion of human outgrowth endothelial cells leads to IL-8-mediated replicative senescence and impaired vasoreparative function. Stem Cells 31:1657-1668.

Medina RJ, O'Neill CL, Sweeney M, Guduric-Fuchs J, Gardiner TA, Simpson DA, Stitt AW (2010) Molecular analysis of endothelial progenitor cell (EPC) subtypes reveals two distinct cell populations with different identities. BMC Med Genomics 3:18.

Morancho A, Hernández-Guillamon M, Boada C, Barceló V, Giralt D, Ortega L, Montaner $J$, Rosell A (2013) Cerebral ischaemia and matrix metalloproteinase-9 modulate the angiogenic function of early and late outgrowth endothelial progenitor cells. J Cell Mol Med 17:1543-1553.

Moubarik C, Guillet B, Youssef B, Codaccioni JL, Piercecchi MD, Sabatier F, Lionel P, Dou L, Foucault-Bertaud A, Velly L, Dignat-George F, Pisano P (2011) Transplanted late outgrowth endothelial progenitor cells as cell therapy product for stroke. Stem Cell Rev Rep 7:208-220.

Nag S (2003) Morphology and molecular properties of cellular components of normal cerebral vessels. Methods Mol Med 89:3-36.

Paneni F, Costantino S, Kränkel N, Cosentino F, Lüscher TF (2016) Reprogramming ageing and longevity genes restores paracrine angiogenic properties of early outgrowth cells. Eur Heart J 37:1733-1737.

Pavlou MP, Diamandis EP (2010) The cancer cell secretome: a good source for discovering biomarkers? J Proteomics 73:1896-1906.

Petty MA, Lo EH (2002) Junctional complexes of the blood-brain barrier: permeability changes in neuroinflammation. Prog Neurobiol 68:311-323.

Prakash R, Carmichael ST (2015) Blood-brain barrier breakdown and neovascularization processes after stroke and traumatic brain injury. Curr Opin Neurol 28:556-564.

Pula G, Mayr U, Evans C, Prokopi M, Vara DS, Yin X, Astroulakis Z, Xiao Q, Hill J, Xu Q, Mayr M (2009) Proteomics identifies thymidine phosphorylase as a key regulator of the angiogenic potential of colony-forming units and endothelial progenitor cell cultures. Circ Res 104:32-40.

Rehman J, Li J, Orschell CM, March KL (2003) Peripheral blood "endothelial progenitor cells" are derived from monocyte/macrophages and secrete angiogenic growth factors. Circulation 107:1164-1169.

Reis C, Wilkinson M, Reis H, Akyol O, Gospodarev V, Araujo C, Chen S, Zhang JH (2017) A look into stem cell therapy: exploring the options for treatment of ischemic stroke. Stem Cells Int 2017:3267352.

Rignault-Clerc S, Bielmann C, Delodder F, Raffoul W, Waeber B, Liaudet L, Berger MM, Feihl F, Rosenblatt-Velin N (2013) Functional late outgrowth endothelial progenitors isolated from peripheral blood of burned patients. Burns 39:694-704.

Rosell A, Morancho A, Navarro-Sobrino M, Martínez-Saez E, Hernández-Guillamon M, Lope-Piedrafita S, Barceló V, Borrás F, Penalba A, García-Bonilla L, Montaner J (2013) Factors secreted by endothelial progenitor cells enhance neurorepair responses after cerebral ischemia in mice. PLoS One 8:e73244.

Sahoo S, Klychko E, Thorne T, Misener S, Schultz KM, Millay M, Ito A, Liu T, Kamide C, Agrawal H, Perlman H, Qin G, Kishore R, Losordo DW (2011) Exosomes from human CD34(+) stem cells mediate their proangiogenic paracrine activity. Circ Res 109:724728.

Santo SD, Seiler S, Guzman R, Widmer HR (2020) Endothelial progenitor cell-derived factors exert neuroprotection in cultured cortical neuronal progenitor cells. Cell Transplant 29:963689720912689.

Schneller D, Hofer-Warbinek R, Sturtzel C, Lipnik K, Gencelli B, Seltenhammer M, Wen M, Testori J, Bilban M, Borowski A, Windwarder M, Kapel SS, Besemfelder E, Cejka P, Habertheuer A, Schlechta B, Majdic O, Altmann F, Kocher A, Augustin HG, et al. (2019) Cytokine-Like 1 is a novel proangiogenic factor secreted by and mediating functions of endothelial progenitor cells. Circ Res 124:243-255

Seminatore C, Polentes J, Ellman D, Kozubenko N, Itier V, Tine S, Tritschler L, Brenot M, Guidou E, Blondeau J, Lhuillier M, Bugi A, Aubry L, Jendelova P, Sykova E, Perrier AL, Finsen B, Onteniente B (2010) The postischemic environment differentially impacts teratoma or tumor formation after transplantation of human embryonic stem cellderived neural progenitors. Stroke 41:153-159.

Serlin Y, Shelef I, Knyazer B, Friedman A (2015) Anatomy and physiology of the bloodbrain barrier. Semin Cell Dev Biol 38:2-6.

Skalnikova H, Motlik J, Gadher SJ, Kovarova H (2011) Mapping of the secretome of primary isolates of mammalian cells, stem cells and derived cell lines. Proteomics 11:691-708

Sobrino T, Hurtado O, Moro MA, Rodríguez-Yáñez M, Castellanos M, Brea D, Moldes O, Blanco M, Arenillas JF, Leira R, Dávalos A, Lizasoain I, Castillo J (2007) The increase of circulating endothelial progenitor cells after acute ischemic stroke is associated with good outcome. Stroke 38:2759-2764.

Stastna M, Van Eyk JE (2012) Secreted proteins as a fundamental source for biomarker discovery. Proteomics 12:722-735.
Tajiri N, Acosta S, Glover LE, Bickford PC, Jacotte Simancas A, Yasuhara T, Date I, Solomita MA, Antonucci I, Stuppia L, Kaneko Y, Borlongan CV (2012) Intravenous grafts of amniotic fluid-derived stem cells induce endogenous cell proliferation and attenuate behavioral deficits in ischemic stroke rats. PLoS One 7:e43779.

Takahashi T, Kalka C, Masuda H, Chen D, Silver M, Kearney M, Magner M, Isner JM, Asahara T (1999) Ischemia- and cytokine-induced mobilization of bone marrowderived endothelial progenitor cells for neovascularization. Nat Med 5:434-438.

Tjalsma H, Bolhuis A, Jongbloed JD, Bron S, van Dijl JM (2000) Signal peptide-dependent protein transport in Bacillus subtilis: a genome-based survey of the secretome. Microbiol Mol Biol Rev 64:515-547

Tousoulis D, Andreou I, Antoniades C, Tentolouris C, Stefanadis C (2008) Role of inflammation and oxidative stress in endothelial progenitor cell function and mobilization: therapeutic implications for cardiovascular diseases. Atherosclerosis 201:236-247

Urbich C, Aicher A, Heeschen C, Dernbach E, Hofmann WK, Zeiher AM, Dimmeler S (2005a) Soluble factors released by endothelial progenitor cells promote migration of endothelial cells and cardiac resident progenitor cells. J Mol Cell Cardiol 39:733-742.

Urbich C, De Souza Al, Rossig L, Yin X, Xing Q, Prokopi M, Drozdov I, Steiner M, Breuss J, Xu Q, Dimmeler S, Mayr M (2011) Proteomic characterization of human early proangiogenic cells. J Mol Cell Cardiol 50:333-336.

Urbich C, Heeschen C, Aicher A, Dernbach E, Zeiher AM, Dimmeler S (2003) Relevance of monocytic features for neovascularization capacity of circulating endothelial progenitor cells. Circulation 108:2511-2516.

Urbich C, Heeschen C, Aicher A, Sasaki K, Bruhl T, Farhadi MR, Vajkoczy P, Hofmann WK, Peters C, Pennacchio LA, Abolmaali ND, Chavakis E, Reinheckel T, Zeiher AM, Dimmeler S (2005b) Cathepsin L is required for endothelial progenitor cell-induced neovascularization. Nat Med 11:206-213.

Vicencio JM, Yellon DM, Sivaraman V, Das D, Boi-Doku C, Arjun S, Zheng Y, Riquelme JA, Kearney J, Sharma V, Multhoff G, Hall AR, Davidson SM (2015) Plasma exosomes protect the myocardium from ischemia-reperfusion injury. J Am Coll Cardiol 65:15251536.

Vizoso FJ, Eiro N, Cid S, Schneider J, Perez-Fernandez R (2017) mesenchymal stem cell secretome: toward cell-free therapeutic strategies in regenerative medicine. Int J Mol Sci 18:1852.

Wang T, Fang X, Yin ZS (2018) Endothelial progenitor cell-conditioned medium promotes angiogenesis and is neuroprotective after spinal cord injury. Neural Regen Res 13:887 895.

Wei L, Fraser JL, Lu ZY, Hu X, Yu SP (2012) Transplantation of hypoxia preconditioned bone marrow mesenchymal stem cells enhances angiogenesis and neurogenesis after cerebral ischemia in rats. Neurobiol Dis 46:635-645.

Weiss N, Miller F, Cazaubon S, Couraud PO (2009) The blood-brain barrier in brain homeostasis and neurological diseases. Biochim Biophys Acta 1788:842-857.

Williams-Karnesky RL, Stenzel-Poore MP (2009) Adenosine and stroke: maximizing the therapeutic potential of adenosine as a prophylactic and acute neuroprotectant. Curr Neuropharmacol 7:217-227.

Wolburg H, Lippoldt A (2002) Tight junctions of the blood-brain barrier: development, composition and regulation. Vascul Pharmacol 38(6):323-337.

Woodruff TM, Thundyil J, Tang SC, Sobey CG, Taylor SM, Arumugam TV (2011) Pathophysiology, treatment, and animal and cellular models of human ischemic stroke. Mol Neurodegener 6:11.

Xing C, Arai K, Lo EH, Hommel M (2012) Pathophysiologic cascades in ischemic stroke. Int J Stroke 7:378-385.

Yamaguchi J, Kusano KF, Masuo O, Kawamoto A, Silver M, Murasawa S, Bosch-Marce M, Masuda H, Losordo DW, Isner JM, Asahara T (2003) Stromal cell-derived factor-1 effects on ex vivo expanded endothelial progenitor cell recruitment for ischemic neovascularization. Circulation 107:1322-1328.

Yang Z, von Ballmoos MW, Faessler D, Voelzmann J, Ortmann J, Diehm N, Kalka-Moll W Baumgartner I, Di Santo S, Kalka C (2011) Paracrine factors secreted by endothelia progenitor cells prevent oxidative stress-induced apoptosis of mature endothelial cells. Atherosclerosis 211:103-109.

Yao Y, Chen ZL, Norris EH, Strickland S (2014) Astrocytic laminin regulates pericyte differentiation and maintains blood brain barrier integrity. Nat Commun 5:3413.

Yellon DM, Davidson SM (2014) Exosomes: nanoparticles involved in cardioprotection? Circ Res 114:325-332.

Zehendner CM, Luhmann HJ, Kuhlmann CR (2009) Studying the neurovascular unit: an improved blood-brain barrier model. J Cereb Blood Flow Metab 29:1879-1884.

Zhang X, Lu A, Li Z, Sun J, Dai D, Qian L (2019) Exosomes secreted by endothelial progenitor cells improve the bioactivity of pulmonary microvascular endothelial cells exposed to hyperoxia in vitro. Ann Transl Med 7:254.

Zhang Y, Ingram DA, Murphy MP, Saadatzadeh MR, Mead LE, Prater DN, Rehman J (2009) Release of proinflammatory mediators and expression of proinflammatory adhesion molecules by endothelial progenitor cells. Am J Physiol Heart Circ Physiol 296:H16751682.

Zhang Y, Li Y, Wang S, Han Z, Huang X, Li S, Chen F, Niu R, Dong JF, Jiang R, Zhang J (2013) Transplantation of expanded endothelial colony-forming cells improved outcomes of traumatic brain injury in a mouse model. J Surg Res 185:441-449.

Zhang ZG, Zhang L, Jiang Q, Zhang R, Davies K, Powers C, Bruggen Nv, Chopp M (2000) VEGF enhances angiogenesis and promotes blood-brain barrier leakage in the ischemic brain. J Clin Invest 106:829-838.

Zhao Z, Nelson AR, Betsholtz C, Zlokovic BV (2015) Establishment and dysfunction of the blood-brain barrier. Cell 163:1064-1078.

Zhou Y, Li P, Goodwin AJ, Cook JA, Halushka PV, Chang E, Fan H (2018) Exosomes from endothelial progenitor cells improve the outcome of a murine model of sepsis. Mol Ther 26:1375-1384.

Zhou Y, Li P, Goodwin AJ, Cook JA, Halushka PV, Chang E, Zingarelli B, Fan H (2019) Exosomes from endothelial progenitor cells improve outcomes of the lipopolysaccharide-induced acute lung injury. Crit Care 23:44

Zhu JH, Wang XX, Zhang FR, Shang YP, Tao QM, Zhu JH, Chen JZ (2008) Safety and efficacy of autologous endothelial progenitor cells transplantation in children with idiopathic pulmonary arterial hypertension: open-label pilot study. Pediatr Transplant 12:650655

C-Editors: Zhao M, Wang L; T-Editor: Jia Y 